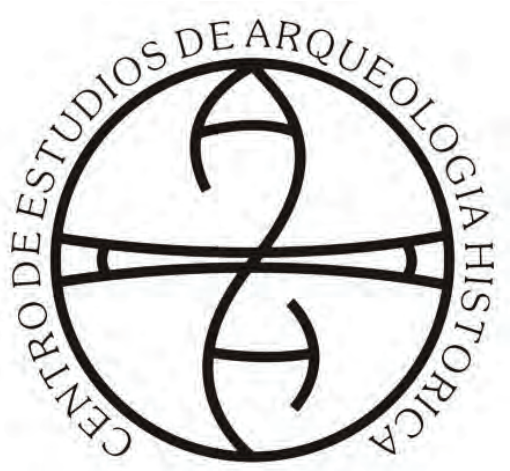

Centro de Estudios de Arqueología Histórica

Universidad Nacional de Rosario

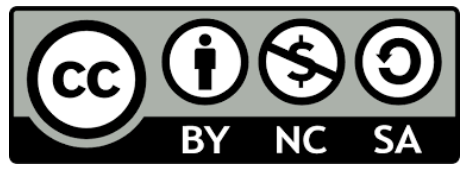

Teoría y Práctica de la Arqueología Histórica

Latinoamericana | Especial: Documentos de Trabajo |

Año I, Número 1 | 2020

Revista del Centro de Estudios de Arqueología Histórica, Facultad de Humanidades y Artes, Universidad Nacional de Rosario https://teoriaypracticaah.unr.edu.ar/index.php/index https://rephip.unr.edu.ar/handle/2133/14804

ISSN en línea: 2591-2801

ISSN versión impresa: 2250-866X

Atribución-NoComercial-CompartirIgual 4.0 Internacional (CC BY-NC-SA 4.0)

https://creativecommons.org/licenses/by-nc-sa/4.0/deed.es

Alejandro García (ID.: https://orcid.org/0000-0002-35375879). Arte rupestre de tiempos históricos en la Sierra Pie de Palo (San Juan)

\title{
ArTe RUPESTRE de TIEMPOS HISTÓRICOS en la Sierra Pie de Palo (San Juan)
}

\author{
Alejandro García *
}

\section{Resumen}

La Sierra Pie de Palo, localizada en el sureste de la provincia de San Juan, contiene un rico patrimonio arqueológico formado principalmente por manifestaciones de arte rupestre. Algunas de éstas corresponden a intervenciones realizadas en tiempos históricos, por lo que resulta de interés conocer sus características, distribución y asociación espacial con el registro previo. Como contribución inicial a ese estudio, el presente trabajo ofrece una clasificación básica del registro rupestre histórico de los cuatro sitios más conocidos del sector y analiza el grado de afectación de los motivos prehispánicos ya existentes en los mismos.

Palabras clave: Arte rupestre, Tiempos históricos, Protección del patrimonio arqueológico, San Juan

\begin{abstract}
The Sierra Pie de Palo, located in the southeast of the province of San Juan, contains a rich archaeological heritage formed mainly by manifestations of rock art. Some of these correspond to interventions carried out in historical times, so it is relevant to know their characteristics, distribution and spatial association with the previous record. As an initial contribution to this study, the present work offers a basic classification of the historical rupestrian record of the four best-known sites in the sector, and analyzes the degree of affectation of the pre-Hispanic motifs already existing in them.
\end{abstract}

Keywords: Rock art, Historical times, Protection of archaeological heritage, San Juan

* Centro de Investigaciones de la Geósfera y la Biósfera (CIGEOBIO), Facultad de Ciencias Exactas, Físicas y Naturales, Universidad Nacional de San Juan (UNSJ), CONICET. E-mail: alegarcia@unsj.edu.ar. 
Teoría y Práctica de la Arqueología Histórica Latinoamericana | Especial: Documentos de Trabajo

Año I, Número 1 | 2020 / ISSN en línea: 2591-2801 | ISSN versión impresa: 2250-866X

\section{Introducción}

La Sierra Pie de Palo, en el centro de la provincia de San Juan, presenta varias quebradas con numerosas representaciones rupestres (Riveros, 2001; Varela, 2001; García, 2019). Parte de esas manifestaciones corresponden a momentos históricos y su análisis resulta de interés para conocer las características de estas intervenciones, su distribución y la eventual afectación de figuras previas. En tal sentido, en el presente artículo se clasifican las representaciones rupestres modernas de cuatro sitios de la región (Quebradas del Molle, del Gato, Pintada y del Pozo del Indio), se identifican las temáticas prevalecientes y se evalúa el grado de alteración antrópica del registro rupestre prehispánico durante los últimos cinco siglos.

\section{Antecedentes}

Los estudios de arte rupestre histórico en la provincia de San Juan tienen un inicio muy reciente, que se remonta a principios del presente siglo. La mayor parte de las investigaciones que involucran la presencia de manifestaciones artísticas de tiempos históricos se han realizado en torno al área de Ischigualasto y a la Sierra de Valle Fértil (Riveros y Varela, 2001; Podestá y Rolandi, 2001; Podestá, Rolandi, Re y Damiani, 2006; Podestá, Re y Romero, 2011; Re, Podestá y Romero, 2011; Bárcena, 2012; Cahiza, 2012; Romero, 2013). En el sector occidental de la provincia sólo se han registrado algunas inscripciones en las quebradas de Agua Blanca y Agua Negra (López y García, 2011; García, 2013). Con respecto al arte rupestre de la Sierra Pie de Palo, los primeros registros fueron realizados por Rusconi $(1947,1962)$ y posteriormente se realizaron algunos estudios arqueológicos (Schobinger, 1962; Consens, Castellano y Dibueno, 1991; García, 2019) y artísticos (Varela, 2001; Riveros, 2001; Varela y Riveros, 2004) pero en todos los casos el foco de atención estuvo constituido por las imágenes prehispánicas.

\section{Sitios analizados}

Los casos estudiados corresponden a la vertiente occidental de la Sierra Pie de Palo (Figura 1). Las representaciones se encuentran en esquistos calcáreos, filitas y mármoles calcáreos precámbricos del Complejo Valle Fértil y, hacia el este, en anfibolitas, esquistos anfibolíticos micáceos y basamento metamórfico de las Sierras Pampeanas del también precámbrico Complejo Pie de Palo (Ramos, et al., 2000).

La Quebrada del Molle Norte (QMN) se encuentra en el sector medio, en el piedemonte contiguo al tramo distal de la Quebrada del Molle. Se trata de un corte profundo de unos $500 \mathrm{~m}$ de extensión, en cuyas paredes se observan numerosos petroglifos que sólo han sido estudiados desde el punto de vista estético (Riveros, 2001; Varela y Riveros, 2004).

La Quebrada del Gato (QG) se sitúa unos $10 \mathrm{~km}$ al sur de la anterior. Se trata de una quebrada muy amplia, en la que se han diferenciado un sector inicial (la parte distal), una quebrada central y una aledaña por el norte denominada "intermedia".

La Quebrada Pintada (QP), de 8,5 km de largo, se ubica en la parte meridional de la vertiente occidental. En ella se han identificado 9 sectores (A, B, C, D, E, F, G, H e I) que presentan numerosas representaciones rupestres prehispánicas y de época histórica.

Finalmente, la Quebrada del Pozo del Indio (QPI), ubicada en el extremo suroeste, tiene una extensión de 3,5 km y presenta unan gran concentración de petroglifos en las paredes del sector proximal, conocido a nivel local como Baño del Indio. Si bien esta quebrada aparece mencionada como "del Tigre" en una antigua carta topográfica, se opta aquí por la denominación utilizada en la Hoja 3169-29-3 de 1986 del Instituto Geográfico Militar.

Arte rupestre de tiempos históricos en la Sierra Pie de Palo (San Juan)

A. GARCÍA 


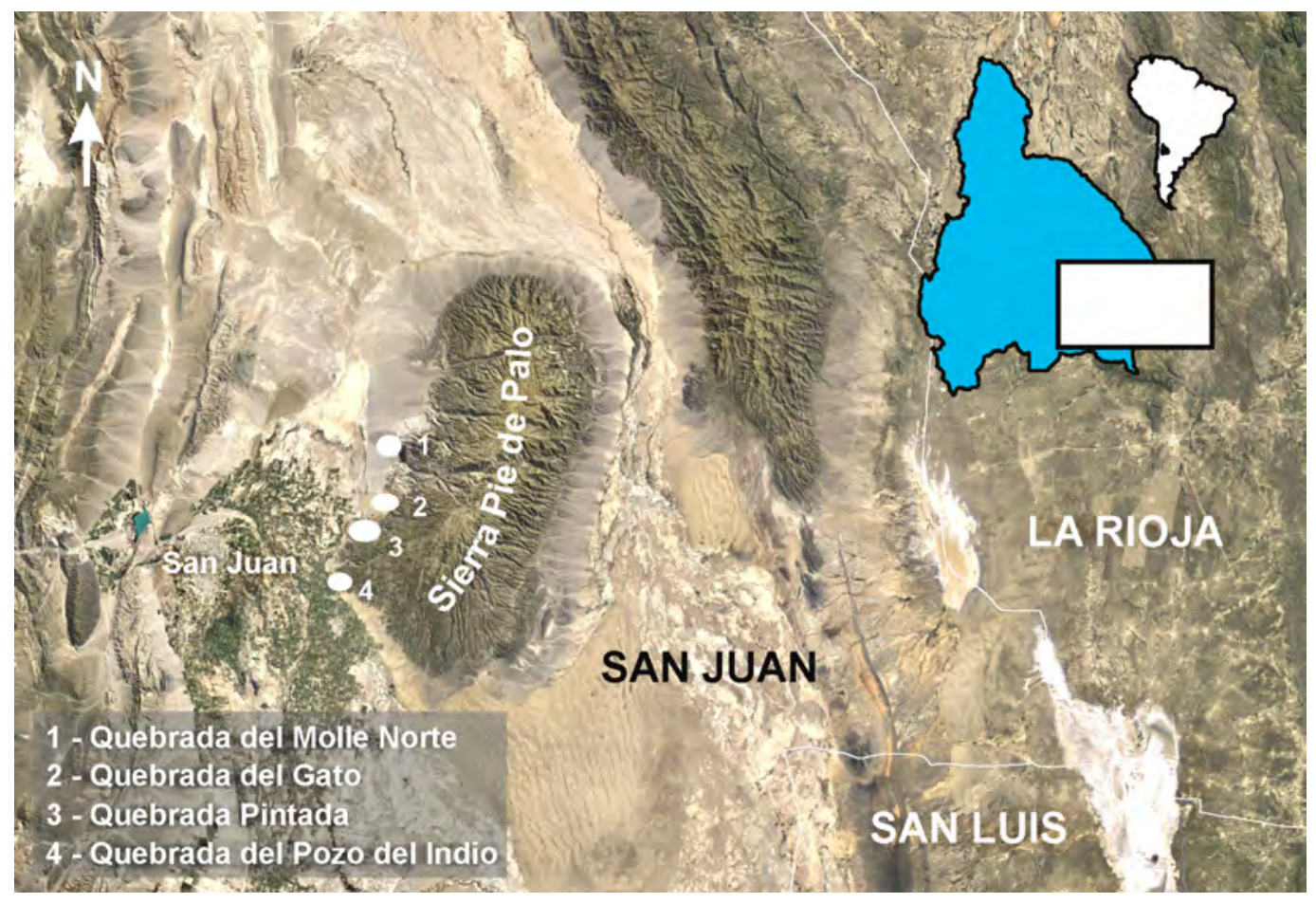

Figura 1. Ubicación de los sitios analizados.

\section{Aspectos metodológicos}

El presente análisis se realizó a través del registro fotográfico digital del arte rupestre de los sitios considerados. Las imágenes fueron tratadas en general con programas específicos que mejoraron la observación de algunos de los motivos (Corel Draw, Adobe Photoshop y D-Stretch), evitando alterar los colores de los trazos y pátinas en los casos de remarcación, agregados, picado o rayado.

A los fines del análisis se consideraron como correspondientes a tiempos históricos las representaciones figurativas que hacen alusión a elementos que sólo pudieron aparecer localmente con posterioridad a la fundación de San Juan (1563) o que presentan trazos sin pátina que evidencian claramente un origen reciente. Con respecto a los motivos no figurativos, sólo se han considerado en este grupo aquellos cuyas líneas o surcos no presentan pátina sino un color blanco muy contrastante del fondo de los soportes y de la pátina de los trazos de las representaciones prehispánicas. En algunos casos se observó una pátina amarillenta clara en motivos evidentemente remarcados, pero no fueron considerados debido a la imposibilidad de distinguir si tal alteración del color era prehispánica o más reciente.

Con respecto a la cantidad de motivos y alteraciones en cada sitio, si bien se ha accedido en varias ocasiones a los sitios, la abundancia y gran dispersión de petroglifos en cada uno de ellos no excluye la presencia de otras manifestaciones no observadas, por lo que los conteos expuestos deben considerarse como mínimos.

En función de su clasificación, los motivos fueron agrupados en tres categorías: los clásicos figurativos y no figurativos, y un tercero de inscripciones que reúne letras, palabras y números (en general, fechas). 


\section{Registro de trazados modernos}

Se identificaron 510 representaciones rupestres modernas: 172 en la QP, 162 en la QPI, 97 en la QG y 79 en la QMN (Tabla 1). En QPI la mayoría son elementos de comunicación occidental (palabras, letras y números; $n=147 ; 90,7 \%)$; en mucha menor medida se observan representaciones figurativas $(n=9$; $5,6 \%)$ y no figurativas $(\mathrm{n}=6 ; 3,7 \%)$. El mismo orden de estas categorías se presenta en $\mathrm{QP}$, donde para una muestra total similar $(\mathrm{n}=172)$ los porcentajes son de 59,9, 20,3 y 19,8 respectivamente.

En cambio, en QG y QMN el grupo mayor está constituido por las representaciones no figurativas ( $\mathrm{n}=81$ y 39, respectivamente), seguido por el de los signos alfabéticos, palabras y números ( $\mathrm{n}=12$ y 34 , respectivamente), con una escasa aparición de motivos figurativos ( $\mathrm{n}=4$ y 6 , respectivamente).

Tabla 1.

Registro de representaciones de tiempos históricos en los sitios analizados.

Q.I: Quebrada Intermedia. Q.C: Quebrada Central.

\begin{tabular}{|c|c|c|c|c|c|c|c|c|}
\hline \multirow{2}{*}{ Motivos } & \multirow{2}{*}{$\begin{array}{l}\text { Q. } \\
\text { Pozo } \\
\text { del } \\
\text { Indio }\end{array}$} & \multicolumn{4}{|c|}{ Quebrada del Gato } & \multirow{2}{*}{$\begin{array}{l}\text { Q. del } \\
\text { Molle } \\
\text { Norte }\end{array}$} & \multirow{2}{*}{$\begin{array}{l}\text { Quebrada } \\
\text { Pintada }\end{array}$} & \multirow{2}{*}{ Total } \\
\hline & & Ini & oQ. I. & Q. C. & Total & & & \\
\hline Motivos figurativos & 9 & 1 & & 3 & 4 & 6 & 35 & 54 \\
\hline $\begin{array}{l}\text { Copia de motivos } \\
\text { indígenas }\end{array}$ & 1 & & & 0 & & 0 & 3 & 4 \\
\hline $\begin{array}{l}\text { Elementos } \\
\text { religiosos }\end{array}$ & 2 & & & 0 & & 0 & 4 & 6 \\
\hline $\begin{array}{l}\text { Motivos no } \\
\text { figurativos }\end{array}$ & 6 & 3 & 11 & 67 & 81 & 39 & 34 & 160 \\
\hline Puntos esparcidos & & 1 & 1 & 4 & 6 & 2 & 3 & 11 \\
\hline $\begin{array}{l}\text { Concentración de } \\
\text { puntos }\end{array}$ & & & 7 & 38 & 45 & 16 & 9 & 70 \\
\hline Líneas de puntos & & 1 & 1 & 4 & 6 & 6 & 3 & 15 \\
\hline Rayones & 3 & 1 & & 3 & 4 & 7 & 5 & 19 \\
\hline Inscripciones & 147 & 3 & 3 & 6 & 12 & 34 & 103 & 296 \\
\hline Siglas - iniciales & 46 & 3 & & 5 & 8 & 12 & 47 & 113 \\
\hline Frases & 7 & & & 1 & 1 & 3 & 4 & 15 \\
\hline Nombres & 66 & & 2 & 0 & 2 & 19 & 33 & 120 \\
\hline Eechas & 28 & & 1 & 0 & 1 & 0 & 19 & 48 \\
\hline Totales & 162 & 7 & 14 & 75 & 97 & 79 & 172 & 510 \\
\hline
\end{tabular}


En general los motivos figurativos son antropomorfos esquemáticos de tono grotesco; también aparecen animales, soles, árboles, un avión, un revólver, etc., y algunos objetos con una clara asociación religiosa, como las cruces y los cálices (Figura 2).

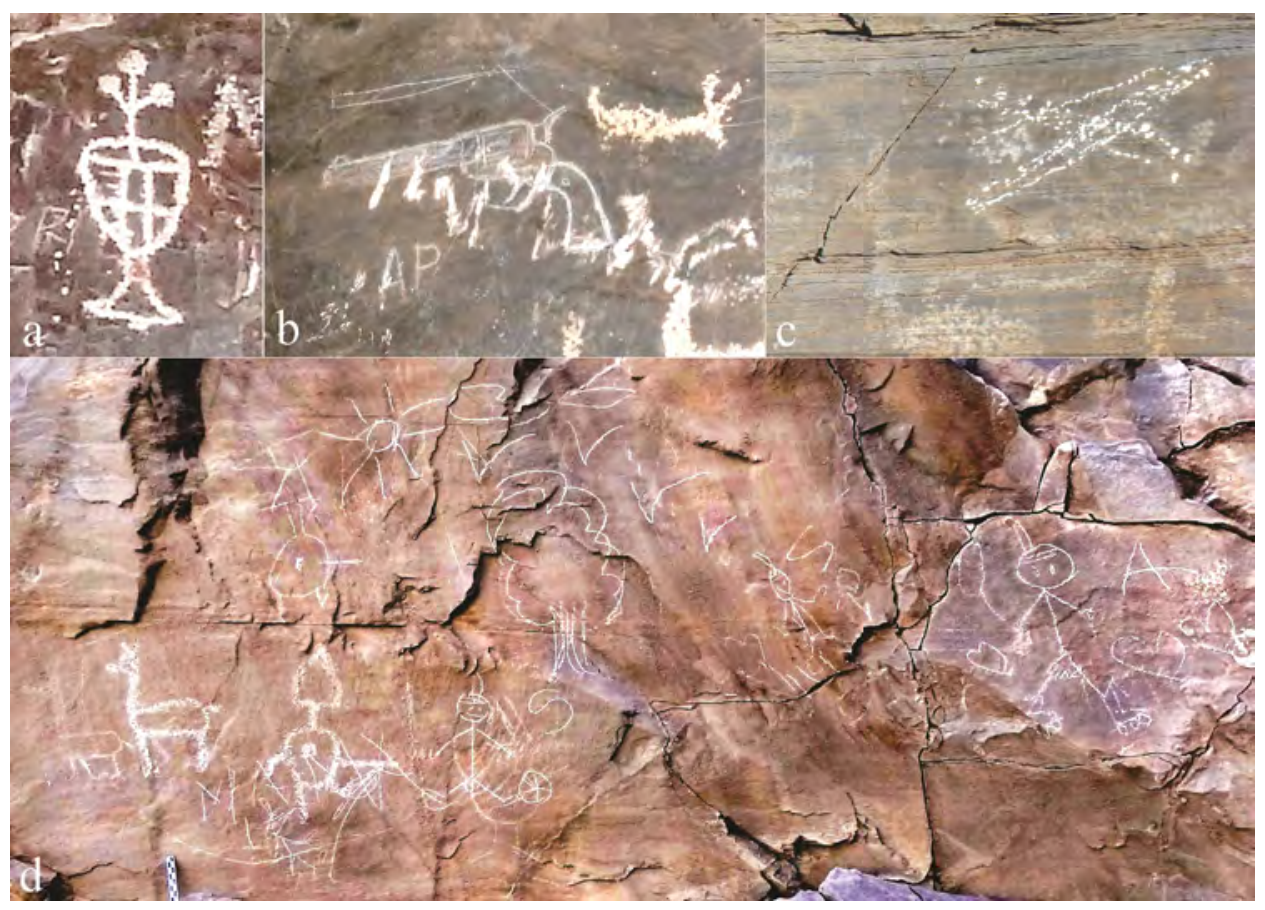

Figura 2. Ejemplos de representaciones figurativas. a) Cáliz de la Quebrada del Pozo del Indio. b) Revólver de la Quebrada del Gato. c) Avión de la Quebrada del Molle Norte. d) Escena grotesca que incluye dos indígenas jugando con una pelota y patinando. Obsérvese la copia de motivos indígenas en el extremo izquierdo.

Un conjunto especial está formado por las representaciones de equinos, de las cuales se observaron 5 en la Quebrada Pintada y una en la del Gato (Figura 3a, b). Las características de cinco de estas figuras son similares a las de los motivos prehispánicos, lo que sugiere que fueron elaboradas por indígenas. Una sola excepción, observada en la Quebrada Pintada (Figura 3b), muestra un estilo diferente, y su autor fue probablemente algún puestero de la región o un obrero de la mina que se encuentra en la parte proximal de la quebrada. 


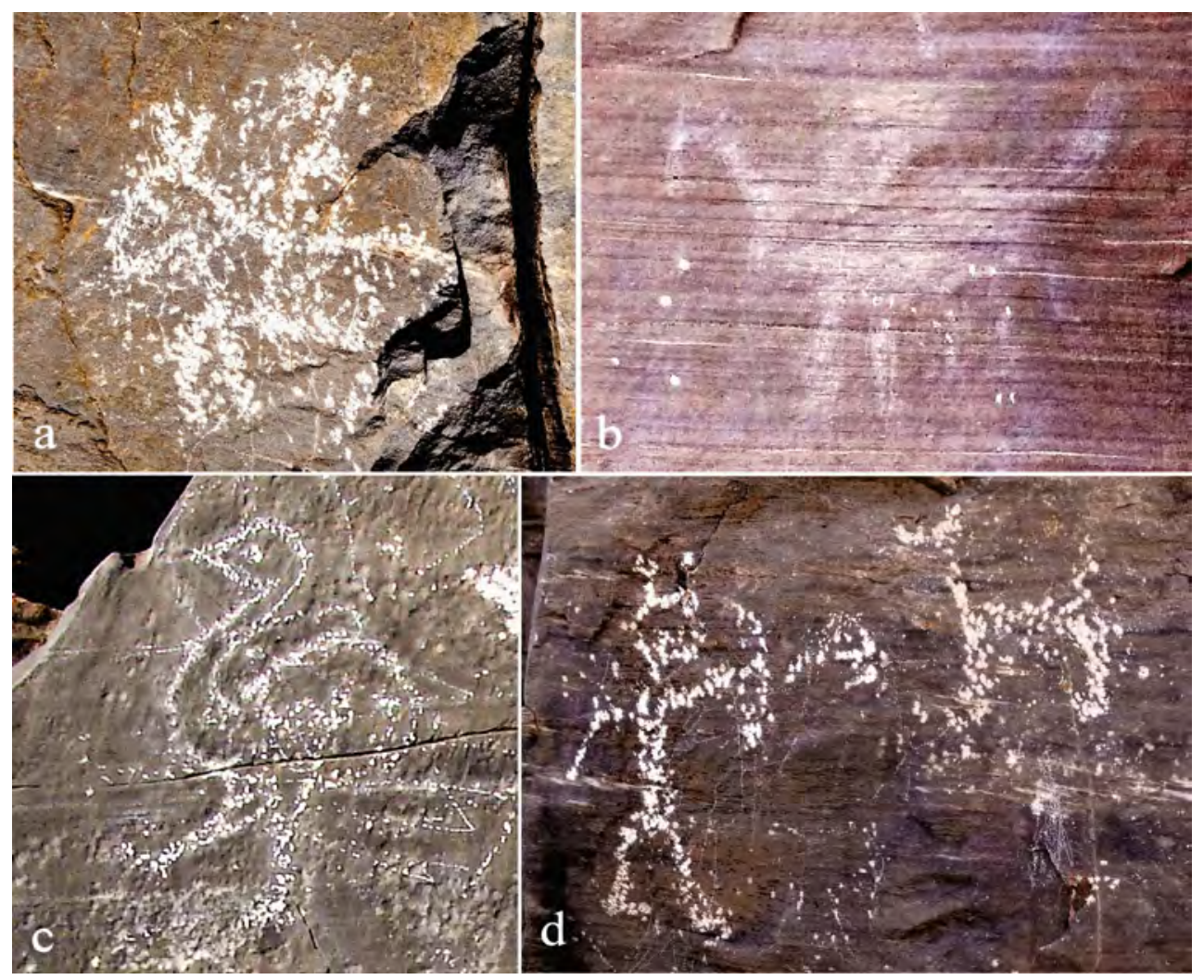

Figura 3. Representaciones de animales e interacción de un antropomorfo moderno con un motivo zoomorfo previo. Origen: Quebradas Pintada (a y d), del Gato (b) y del Molle Norte (c).

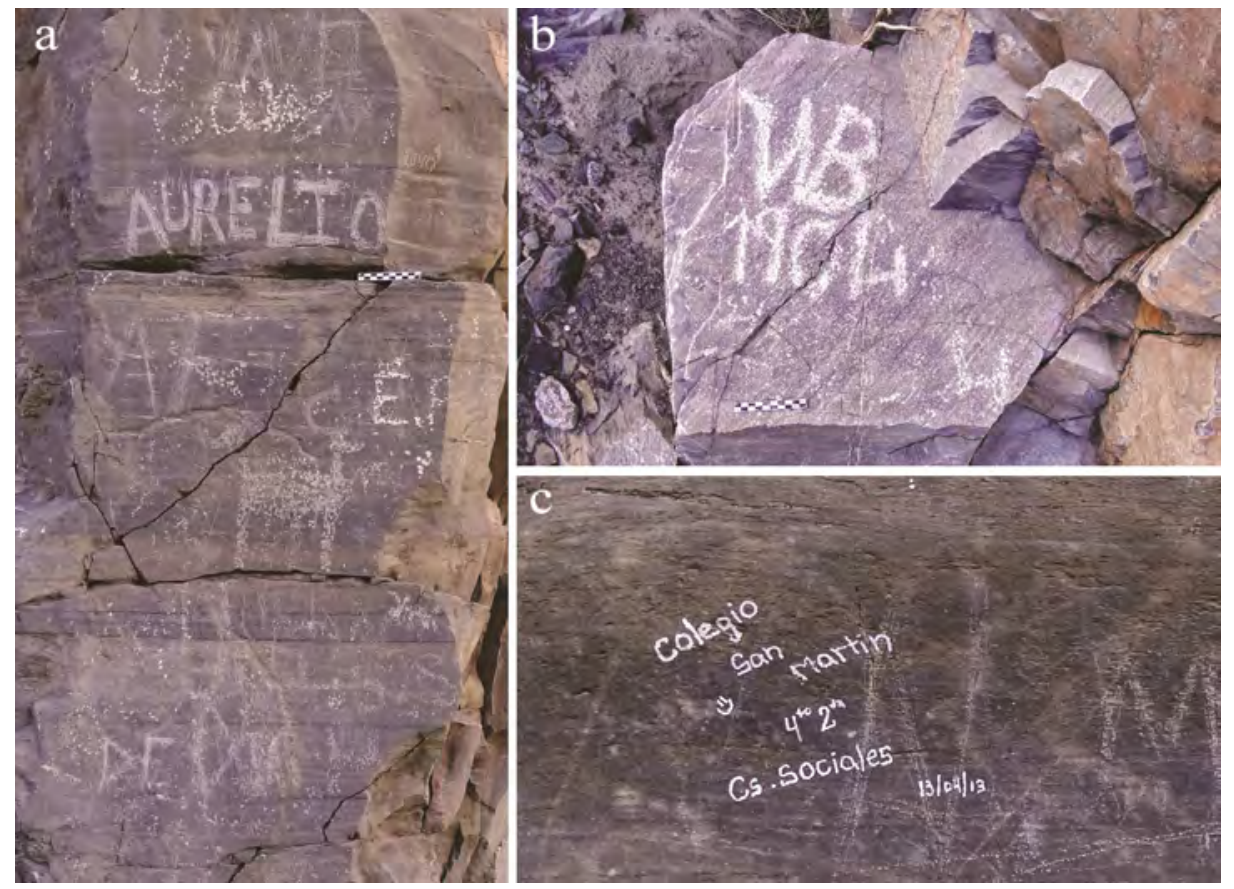

Figura 4. Ejemplos de inscripciones. A y b) QP; c) QPI. 
La mayor parte de los grabados está constituida por inscripciones, en forma de letras aisladas, nombres, frases y fechas (Figura 4). Estos elementos se observan fundamentalmente en las quebradas del Pozo del Indio y Pintada. Las frases son escasas y a veces difíciles de leer debido a su deterioro. En general se trata de temas personales (por ejemplo, las clásicas declaraciones de amor) pero en algunos casos se observa un trasfondo político ("Malvinas argentinas") o religioso ("Jesú [sic] te ama", "Dios es amor"). Las fechas ocupan un lugar importante $(\mathrm{n}=48 ; 16,2 \%)$ y se extienden desde principios del siglo XX $(1904,1918,1921$, etc.) hasta 2013. Las iniciales y los nombres dominan ampliamente esta categoría $(\mathrm{n}=233 ; 78,7 \%)$. Los nombres son casi exclusivamente antropónimos (ya sea nombres de pila o apellidos) y ocasionalmente topónimos o nombres de instituciones (Figura 4c). La calidad de las inscripciones es muy variable, desde simples rayones hasta elaboradas líneas de puntos, y excepcionalmente se observan algunas realizadas con marcadores modernos.

\section{Registro de alteraciones de representaciones indígenas}

Uno de los aspectos más importantes relacionados con el estado de preservación de las representaciones analizadas es el elevado grado de alteración antrópica. Si bien en algunos casos se observan rayones realizados sobre motivos indígenas poco visibles, en general se trata de claras perturbaciones intencionales destinadas a afectar negativamente las representaciones previas. Se identificaron 393 casos de alteración en el conjunto de las cuatro quebradas (Tabla 2). Las principales modificaciones son la remarcación y el tizado de motivos $(\mathrm{n}=269 ; 68,4 \%)$. La remarcación se observa fundamentalmente en QG y QMN, y en muchos casos se trata de picados relativamente cuidadosos que abarcan la totalidad de los motivos y les dan una marcada visibilidad en relación a los restantes.

Tabla 2.

Registro de alteraciones en los sitios analizados. Q.I: Quebrada Intermedia. Q.C: Quebrada Central.

\begin{tabular}{|c|c|c|c|c|c|c|c|c|}
\hline \multirow{2}{*}{ Alteración Sitio } & \multirow{2}{*}{$\begin{array}{l}\text { Q. Pozo } \\
\text { del } \\
\text { Indio }\end{array}$} & \multicolumn{4}{|c|}{ Quebrada del Gato } & \multirow{2}{*}{$\begin{array}{l}\text { Q. del } \\
\text { Molle } \\
{ }^{1} \text { Norte }\end{array}$} & \multirow{2}{*}{$\begin{array}{l}\text { Quebrada } \\
\text { Pintada }\end{array}$} & \multirow{2}{*}{ Total } \\
\hline & & Inicio & Q. I. & Q. C. & Total & & & \\
\hline $\begin{array}{l}\text { Remarcación de } \\
\text { motivos }\end{array}$ & & 1 & & 51 & 52 & 80 & 18 & 150 \\
\hline $\begin{array}{l}\text { Agregado a motivos } \\
\text { indígenas }\end{array}$ & & & & 2 & 2 & 0 & 5 & 7 \\
\hline $\begin{array}{l}\text { Rayado de motivos } \\
\text { indígenas }\end{array}$ & 21 & & & 0 & 0 & 47 & 8 & 76 \\
\hline $\begin{array}{l}\text { Picado de motivos } \\
\text { indígenas }\end{array}$ & 9 & & & 7 & 7 & 21 & 3 & 40 \\
\hline Tizado & 29 & & 4 & 1 & 5 & 0 & 85 & 119 \\
\hline $\begin{array}{l}\text { Motivo afectado por } \\
\text { pintura moderna }\end{array}$ & & & & & & & 1 & 1 \\
\hline Totales & 59 & 1 & 4 & 61 & 66 & 148 & 120 & 393 \\
\hline
\end{tabular}

Arte rupestre de tiempos históricos en la Sierra Pie de Palo (San Juan)

A. GARCÍA 
En las quebradas del Pozo del Indio y del Gato se observaron muchos casos de tizado de representaciones de difícil visibilidad; a veces la afectación sólo se distingue en los bordes, mientras que en otras ocasiones se extiende al interior de los motivos (Figura 5). Frecuentemente sólo se distinguen exiguos restos del tizado en el interior o los bordes de las figuras, debido a la erosión causada por los agentes naturales. Este fenómeno se observa fundamentalmente en QP. Más escasos son los casos de agregado de trazos a motivos indígenas, que sólo se han identificado en QMN y QP.

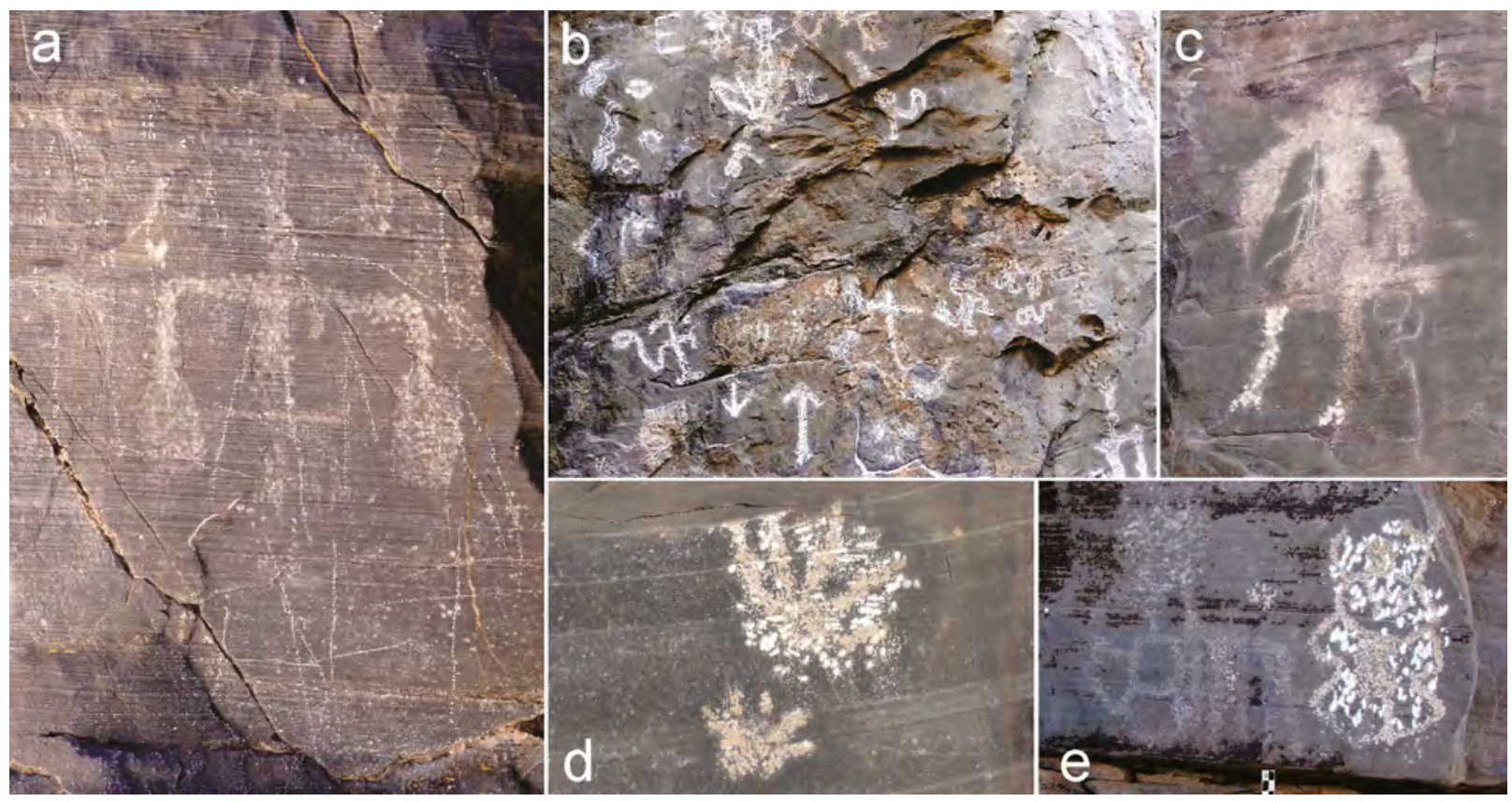

Figura 5. Alteraciones registradas. a) Rayado (QP); b) Representaciones tizadas (QPI); c) Remarcado (QPI); d y e) Picado (QMN).

\section{Sobre el contenido y distribución de las representaciones modernas}

Con excepción de algunas inscripciones e imágenes figurativas (sobre todo las de caballos y algunas religiosas), el registro histórico analizado muestra una marcada falta de cuidado en su elaboración. Las representaciones figurativas son muy simples, realizadas por rayado de la superficie, y las no figurativas muestran trazos o punteados dispersos cuya finalidad es difícil de percibir. En conjunto, el contraste con la inversión de tiempo y el grado de esmero y detalle de las representaciones prehispánicas es llamativo.

Pero lejos de constituir un conjunto homogéneo, los sitios analizados presentan realidades distintas acerca de la producción de arte rupestre. El primer elemento que sobresale es la mayor cantidad de motivos $(65,5 \%)$ y, fundamentalmente, de inscripciones $(84,5 \%)$, en QPI y QP. Esta situación se explica fundamentalmente por la mayor cercanía a lugares poblados y facilidad de acceso a estos sitios. En efecto, ambas quebradas están situadas muy próximas a la localidad denominada Villa Dominguito y a numerosas propiedades rurales. Desde este sector poblado las distancias máximas a QPI y QP son de sólo ca. 2 y $4 \mathrm{~km}$, respectivamente. Por su parte, las distancias máximas a QMN y QG desde los grupos de casas más cercanos, utilizando los únicos caminos disponibles para acceder en vehículo son de 9 y $22 \mathrm{~km}$. Evidentemente, la gente puede llegar (y de hecho, lo hace) a estos últimos lugares pero las dificultades 
Teoría y Práctica de la Arqueología Histórica Latinoamericana | Especial: Documentos de Trabajo

Año I, Número 1 | 2020 / ISSN en línea: 2591-2801 | ISSN versión impresa: 2250-866X

son algo mayores que en los dos primeros casos, tanto por el variable estado de los caminos como por la presencia de emprendimientos mineros en las cercanías de ambas quebradas. En los primeros casos, el registro sugiere que (al igual que en la actualidad) desde principios del siglo XX los pobladores locales consideraron estos sitios como lugares atractivos para realizar visitas de fin de semana con amigos o parientes, lo que ya era mencionado por Rusconi (1947) hace más de 70 años. En particular, el fácil acceso a QPI hace que sea un sitio muy conocido a nivel local y visitado frecuentemente por distintos grupos (universitarios, religiosos, scouts, organizadores de trekkings, periodistas, etc.).

Cabe señalar que las inscripciones de estos sitios no guardan relación con las registradas en Ischigualasto y en la Sierra de Valle Fértil (e.g., Podestá et al., 2006, 2011; Re et al., 2011; Romero 2013), ya que éstas corresponden generalmente a iniciales y marcas de arrieros que no han sido observadas en el área analizada.

Con respecto a QMN y QG es interesante notar una aparente menor necesidad de trascendencia personal de sus visitantes mediante el registro de iniciales o nombres, lo que ha sido cambiado (sobre todo en QMN) por la realización de trazos, raspados y puntos. Sin embargo, estas acciones tuvieron consecuencias igualmente negativas, ya que contribuyeron al deterioro (en algunos casos, extremo) del arte rupestre prehistórico. De hecho, la cantidad de alteraciones permanentes en estos dos sitios es mucho mayor que en los otros, ya que si bien el total de motivos perturbados en QPI y QP es alto (59 y 120 respectivamente), gran parte de esas modificaciones corresponden al tizado de los motivos, del que quedan señales en distinto grado según las condiciones locales. Dado que esta afectación es parcial o totalmente reversible según cada caso (y por lo tanto reviste una gravedad menor que el picado o el rayado de motivos), las alteraciones permanentes en estos sitios serían solamente 30 en QPI y 35 en QP. No obstante, en estos sitios la incidencia de las inscripciones no es menor, ya que gran parte de ellas ha sido insertada en paneles con motivos indígenas, modificando irreversiblemente la visión general de los conjuntos y, en ocasiones, superponiéndose a las representaciones prehispánicas.

Un aspecto interesante de los tizados es que pueden ser fechados con cierta precisión y atribuidos a Carlos Rusconi, investigador mendocino de mediados del siglo XX. En efecto, este autor relata que entre el 16 y el 21 de diciembre de 1946 realizó una visita al área, practicó algunas excavaciones y registró los petroglifos de varias quebradas, incluidas la del Gato y la Pintada (Rusconi, 1947). Según este autor, "para obtener mayores detalles he reforzado con tiza todos los conjuntos" (Rusconi, 1947, p.134), y en otras ocasiones realizó "algunos ensayos con el fin de distinguir los golpes de percusión dejados por indígenas" y por visitantes recientes que van a "pasar un día de campo" (Rusconi, 1962, p. 559). Por lo tanto, los tizados de estos sitios, y posiblemente también los de QPI, corresponderían a este autor y habrían sido realizados en una época en que esa práctica se consideraba inofensiva. Asimismo, varios de los conjuntos de puntos registrados podrían explicarse por sus "ensayos".

Entre los motivos figurativos modernos se destacan los de carácter religioso. En QP aparecen dos cruces cristianas alargadas típicas con pedestales semicirculares y la figura esquemática de un ángel, además de una cruz con cuernos (García, 2019). En QPI aparecen dos copas o cálices y varias inscripciones religiosas. Si bien estas apariciones podrían ser manifestaciones personales de fe, la inserción de los clérigos en algunas comunidades locales es muy fuerte, por lo que tales imágenes e inscripciones podrían corresponder a eventos grupales que pudieron contar con participación de sacerdotes. En este sentido, es interesante notar que este tipo de obras no aparecen en QMN y QG, cuyo acceso desde los centros poblados puede realizarse completamente a pie en el lapso de un día. 
Teoría y Práctica de la Arqueología Histórica Latinoamericana | Especial: Documentos de Trabajo

Año I, Número 1 | 2020 / ISSN en línea: 2591-2801 | ISSN versión impresa: 2250-866X

\section{Alteración y protección de los sitios analizados}

Las quebradas de la vertiente occidental de la Sierra Pie de Palo y sus petroglifos fueron declarados en 2001 como bien patrimonial y las manifestaciones de arte rupestre fueron consideradas "Monumento Histórico - Artístico, Sitio Histórico y Sitio Arqueológico", en conformidad con la Ley Provincial N ${ }^{\circ}$ 6.801 que regula la protección del patrimonio cultural y natural de la provincia. Sin embargo, como sucede frecuentemente, este tipo de declaraciones son realizadas con la mejor voluntad e intención pero no son acompañadas por proyectos de investigación y gestión, ni por acciones de control efectivas y permanentes que permitan un resguardo eficaz de los bienes declarados. Es cierto que la mayoría de las alteraciones fechadas son de época anterior pero la cantidad de inscripciones correspondiente a este siglo es igualmente importante. La necesidad de una solución práctica y sostenida en el tiempo para la protección de los sitios analizados, recurrentemente señalada en los medios periodísticos locales, es congruente con el alto grado de alteración registrado en el marco del presente análisis.

A diferencia de los sitios con arte rupestre localizados en algunas quebradas cordilleranas del oeste provincial (Conconta, Agua Blanca, etc.) y de la precordillera (por ejemplo, Higueritas y los ubicados en ladera de las Sierras Azules de Zonda), en los que la actividad particular más agresiva es la sustracción de rocas con petroglifos (porque en general ese es el soporte de las representaciones rupestres), en los emplazamientos de la Sierra Pie de Palo, en los que las imágenes se localizan en amplios frentes rocosos de difícil remoción, las intervenciones directas son las que producen el mayor daño. Algunas situaciones específicas permiten apreciar claramente la seriedad del problema. Por un lado, resulta llamativo que alumnos de cuarto año del área de Ciencias Sociales de un colegio sanjuanino hayan escrito sus nombres en una roca del sitio QPI, tanto por la orientación de sus estudios (que debería reflejar un mayor conocimiento y concientización del tema) como por el hecho de haber realizado esta acción sobre un soporte que contenía motivos rupestres. La inscripción del nombre del colegio sugiere además que la visita al lugar pudo formar parte de actividades educativas oficiales y guiadas por un profesor o autoridad, lo que torna más inexplicable la situación. Las inscripciones indicarían la realización de al menos tres visitas al lugar, dos de ellas en días sábados (11/6/11 y 13/4/13). Por otro lado, es muy preocupante la gran cantidad de intervenciones no reversibles sobre los motivos rupestres. ¿Qué motiva a una persona a invertir parte de su tiempo en acceder a un sitio con manifestaciones rupestres sólo para destruirlas o alterarlas? Además de ser sumamente complejo de abordar, el aspecto vinculado con los problemas educativos, psicológicos y sociales es demasiado evidente como para hacer hincapié en él; en cambio, vale la pena señalar que estos actos de vandalismo prueban que cualquier actividad relacionada con la socialización y gestión de esta clase de bienes debe contemplar claramente el control permanente de todas las facetas involucradas en el acceso y estadía de visitantes en los sitios arqueológicos. De igual forma, parece claro que mientras se logran las condiciones básicas para la elaboración de planes de manejo específicos de estos lugares, las autoridades provinciales deberían plantearse la necesidad de avanzar en el diseño de medidas de corto plazo encaminadas a su efectiva protección.

\section{Consideraciones finales}

Las quebradas más conocidas de la vertiente occidental de la Sierra Pie de Palo ofrecen un abundante y variado registro de inscripciones y motivos rupestres de época histórica. Aunque en general las representaciones figurativas son relativamente escasas, las proporciones de las categorías analizadas varían en los distintos sitios. Sin embargo, todos tienen en común algunos elementos: a) el libre acceso de la

Arte rupestre de tiempos históricos en la Sierra Pie de Palo (San Juan)

A. GARCÍA

Páginas 9-20 
Teoría y Práctica de la Arqueología Histórica Latinoamericana | Especial: Documentos de Trabajo

Año I, Número 1 | 2020 / ISSN en línea: 2591-2801 | ISSN versión impresa: 2250-866X

gente; b) el limitado interés de al menos una parte de sus visitantes en no afectar el patrimonio rupestre local; c) la profunda inclinación de una parte de esas personas a alterar las obras indígenas que precisamente concitan su atención en esos lugares; d) la modificación importante de las características visibles de muchos motivos indígenas. Como resultado, sobre todo por las numerosas remarcaciones, durante los últimos cien años se ha perdido valiosa información que actualmente obstaculiza de manera importante cualquier intento de estudio sistemático integral del arte rupestre de estos sitios.

Desde un punto de vista práctico, frente a la ausencia de medios que permitan la protección efectiva de todos los sitios de la región resulta apremiante su registro detallado, aun cuando los estudios detallados no se realicen a corto o mediano plazo, ya que parece prioritaria la necesidad de salvaguardar la mayor parte de los datos actualmente disponibles. La elaboración de un diagnóstico realista del estado de los sitios y de los riesgos de alteración es otro pilar sobre el que deben apoyarse las futuras medidas tendientes a su preservación, y en ese sentido el presente trabajo constituye una base inicial. Alternativamente, contribuye también al conocimiento de una realidad poco conocida y espacialmente restringida, cuya articulación con futuros estudios similares en otros sectores del territorio provincial permitirá apreciar los distintos matices de la intervención humana en los sitios con arte rupestre durante la época histórica.

\section{Agradecimientos}

Este trabajo fue realizado en el marco de los proyectos PIP 2014-16 Nº640CO (CONICET) Ocupación humana prehispánica tardía y condiciones paleoambientales en la vertiente occidental de la Sierra Pie de Palo (San Juan) y F1039 UNSJ. Agradezco la valiosa participación del Lic. Oscar Riveros, la Lic. Anabel Rodríguez y la Sra. Susana Carrizo en las tareas de prospección y las oportunas sugerencias recibidas en la instancia de evaluación.

\section{Referencias bibliográficas}

BÁRCENA, J. R. (2012). Grabados rupestres del Área de la Quebrada de la Chilca, Vertiente Occidental de la Sierra de Valle Fértil, Provincia de San Juan, Argentina. El Sitio La Chilca Pintada. Anales de Arqueología y Etnología 65-67, 89-120.

CAHIZA, P.A. (2012). Las piedras marcadas. Representaciones rupestres del piedemonte occidental de la Sierra de Valle Fértil, San Juan. Anales de Arqueología y Etnología 65-67, 87- 101.

CONSENS, M., CASTELlANO, A. y DiBUENO, C. (1991). Análisis de rasgos en el arte rupestre del Río San Juan. En M. Podestá, M.I. Hernández Llosas y S.F. Renard de Coquet, (Eds.), El arte rupestre en la arqueología contemporánea (pp. 92-100). Buenos Aires: Salón Gráfico Integral S.R.L.

GARCÍA, A. (2013). Recursos Arqueológicos de la Quebrada de Agua Negra. En A. García (Ed.), El Corredor Bioceánico en San Juan. Recursos culturales y naturales del sector andino (pp. 83-108). San Juan: EFU.

GARCÍA, A. (2019). Relevamiento del arte rupestre de la Quebrada Pintada (Sierra Pie de Palo, San Juan). Revista Sociedades de Paisajes Áridos y Semi-Áridos, XII (2), 274-292.

LÓPEZ, C. y GARCÍA, A. (2011). Análisis preliminar de los petroglifos de la Quebrada de Agua Blanca. En C. Mayol Laferrère, F. Ribero y J. Díaz (Comps.), Arqueología y Etnohistoria del Centro-Oeste

Arte rupestre de tiempos históricos en la Sierra Pie de Palo (San Juan)

A. GARCÍA

Páginas 9-20 
Teoría y Práctica de la Arqueología Histórica Latinoamericana | Especial: Documentos de Trabajo Año I, Número 1 | 2020 / ISSN en línea: 2591-2801 | ISSN versión impresa: 2250-866X

Argentino (pp. 363-374). Río Cuarto: Universidad Nacional de Río Cuarto.

PODESTÁ, M. y ROLANDI, D. (2001). Marcas en el desierto. Arrieros en Ischigualasto (San Juan, Argentina). Boletín de la Sociedad de Investigación del Arte Rupestre de Bolivia, 15, 63-73.

PODESTÁ, M., ROLANDI, D., RE, A. y DAMIANI, O. (2006). Arrieros y marcas de ganado. Expresiones de arte rupestre de momentos históricos en el desierto de Ischigualasto. En D. Fiore, y M. M. Podestá (Eds.), Tramas en la Piedra. Producción y Usos del Arte Rupestre (pp. 169-190). Buenos Aires: WAC, AINA, SAA y Altuna Impresores.

PODESTÁ, M., RE, A. y ROMERO, G. (2011). Visibilizando lo invisible. Grabados históricos como marcadores idiosincráticos en Ischigualasto. En L. Núñez y A. Nielsen (Eds.), En ruta. Arqueología, historia y etnografía del tráfico sur andino (pp. 341-372). Córdoba: Encuentro Grupo Editor.

RAMOS, V., VUJOVICH, G., CARDÓ, R., PÉREZ, L., PELICHOTTI, R., GODEAS, M. y PUCCI, J.C. (2000). Hoja Geológica 3169-IV San Juan. Provincia de San Juan. Boletín, 243. Buenos Aires: Secretaría de Energía y Minería.

RE, A., PODESTÁ, M. y ROMERO, G. (2011). Ocupaciones humanas y grabados rupestres del norte de la sierra de Valle Fértil (provincia de San Juan). Comechingonia, 15, 65-92.

RIVEROS, G. (2001). Análisis del arte rupestre de la Quebrada del Molle Sur (Dpto. Angaco, San Juan). Publicaciones, 25, 3-44.

RIVEROS, G. y VARELA, A. (2001). Ischigualasto: estudio preliminar del arte rupestre. Publicaciones, $25,131-147$.

ROMERO, G. (2013). Los grabados prehispánicos del noreste de San Juan. Arte rupestre y circulación de información en ambientes áridos. Tesis de Licenciatura. Inédita. Buenos Aires: Facultad de Filosofía y Letras, UBA.

RUSCONI, C. (1947). Petroglifos de la Sierra Pie de Palo. Revista Geográfica Americana, XXVIII (168), 129-135.

RUSCONI, C. (1962). Poblaciones pre y posthispánicas de Mendoza. Volumen III. Arqueología. Mendoza.

SCHOBINGER, J. (1962). Representaciones de máscaras en los petroglifos del occidente argentino. Anthropos, 57, 683-699.

VARELA, A. (2001). Petroglifos de la Quebrada del Molle Norte (Dpto. Angaco, San Juan). Análisis Estético. Publicaciones, 25, 45-130.

VARELA, A. y RIVEROS, M.G. (2004) Arte rupestre de San Juan: Petroglifos de Angaco (Obra abierta en el espacio y el tiempo). Chungará Revista de Antropología Chilena 36(2), 663-671.

Recibido: 30 de abril de 2020.

Aceptado: 30 de junio de 2020.

Arte rupestre de tiempos históricos en la Sierra Pie de Palo (San Juan)

A. GARCÍA

Páginas 9-20 